\title{
Analysis of heavy metal contents in some commercial turmeric samples available at Dhaka, Bangladesh
}

\author{
Md. Ataur Rahman, Taslima Akter", Rahima Akter, Bidduth Kumar Sarkar and \\ Md. Rafiquzzaman \\ Department of Pharmacy, Jahangirnagar University, Savar Dhaka-1342, Bangladesh
}

\begin{abstract}
Nowadays, the use of spices and other herbs have extensively increased due to their medicinal values all over the world. However, the monitoring of heavy metal contamination in spices has also been increased in recent years. A study has been conducted to determine the concentration of eight heavy metals such as Lead (Pb), Cadmium (Cd), Chromium $(\mathrm{Cr})$, Arsenic (As), Zinc $(\mathrm{Zn})$, Iron $(\mathrm{Fe})$, Copper $(\mathrm{Cu})$ and Manganese $(\mathrm{Mn})$ in mainly three different types of turmeric samples (Curcuma longa). The turmeric samples analyzed were (i) Unpacked bulk powder available at three different local markets in Dhaka (ii) Packed and marketed by three branded companies, and (iii) Raw turmeric directly collected from different local farmlands. The samples were analyzed using Atomic Absorption Spectroscopy (AAS). The concentration of most of the heavy metals were found within the limit recommended by WHO $(6.0000 \mathrm{ppm})$ except lead (12.3469 ppm) in unpacked-3 bulk sample. This study also showed the concentration of heavy metals were present in a lower amount in packed power samples compared to unpacked bulk powder samples. The result of this analysis would be helpful for public awareness in consumption of different spices. The concerned authorities who are responsible for monitoring and regulating the food chain in the market in our country may also get a great message about heavy metal contamination of spices.
\end{abstract}

Key words: Commercial turmeric powder, Heavy metal, Toxicity.

\section{INTRODUCTION}

Spices are different parts of the plant like leaves, roots, fruits, flowers, or stems used as coloring, flavoring or preserving agent in food (Hirasa \& Takemasu, 1998). There are varieties of vegetables and curries in the daily food list of the Indian subcontinent (Marian $\&$ Cosmos, 2010). Many of these spices have antimicrobial properties and that is why they are more commonly used in processing foods in warmer climates where more infectious diseases prevail. Spices are used in medicine because of their antioxidant and antimicrobial action. They are also used in religious rituals, cosmetics, or as vegetables. Like the cuisine of many cultures, different types of spices make Bangladeshi dishes distinctive, palatable, aromatic and acceptable (Hinneburg et al., 2006). The bulk of the dry material of spices contains carbohydrates and organic compounds having different functional groups (Sing \& Garg, 2006; Ajasa et al., 2004). Many of these spices have been recorded to show anti-diabetic, anti-inflammatory and antihypertensive potential. Many common spices have outstanding health benefits (Srinivasan, 2005).

\footnotetext{
* Corresponding author. Email: akter_taslima15@yahoo.com
} 
Trace elements are naturally occurring, homogeneous and the inorganic substance required in humans in amounts less than $100 \mathrm{mg} /$ day (Gupta et al., 2003). Natural food spices such as pepper, turmeric and mustard have been reported to contain significant quantities of some trace elements. These trace metals in spices and medicinal plants play important role in enzymes of living cells (Manju, 2015). The term heavy metal refers to any metallic chemical element that has a relatively high density (Gupta et al., 2003) greater than $4.5 \mathrm{~g} / \mathrm{cm}^{3}$ and is toxic or poisonous at low concentrations. Criteria used to define heavy metals have included density, atomic weight, atomic number, periodic table position. Trace and heavy metals above the permissible level affect human health and may result in illness to the human fetus, abortion, preterm labor and mental retardation to children. Adults also may experience high blood pressure, fatigue, kidney and brain troubles. Heavy metal may arrive and pollute plant, vegetables, fruits and canned foods through the air, water and soil during cultivation and also during industrial processing and packaging. Some businessmen during processing their spices add color (that may contain heavy metal) to spices to attract customers. Heavy metals may get into spices and foods during seasoning them due to damaging of machinery parts in some industries. Heavy metals are thus entering into our food chain through these spices which are used for our daily life. The process of preparation, handling and packaging are thus making spices a potential source of food contamination, which results in serious health complications. The presence of essential metals such as iron, zinc, copper, and nickel are very useful for the healthy growth of the body although very high levels are intolerable. Other metals like mercury, lead, chromium, cadmium etc. are toxic at very low concentrations (Manju, 2015). The spices that may be contaminated with trace and heavy metals may result in accumulation of these metals in human organs and leads to different health complications. The study of these heavy metals is very crucial because they have potential hazardous effect in human health. In Bangladesh, spices have varied uses however, there is little information available about the safety of these spices with respect to heavy metal contamination. Keeping this idea in mind the present study has been designed to investigate some heavy metal concentration in unpacked bulk turmeric powder as well as packed branded turmeric powder product collected from different markets at Dhaka and in raw turmeric samples which were collected directly from different farmlands at Savar, Dhaka, Bangladesh.

\section{MATERIALS AND METHODS}

Sample Collection: Turmeric powder that is sold as an unpacked bulk form was bought from three different local markets of Dhaka, Bangladesh. Then those were kept in polyethylene bags and labeled as unpacked - 1, unpacked - 2 and unpacked - 3 . Turmeric powder marketed in the sealed poly pack of three different brands were bought from market and were coded as packed - 1, packed - 2 and packed - 3. Three more samples were raw turmeric spice collected directly from Savar area such as Savar dairy farm farmland, Islamnagar farmland, Kalabagan farmland and those samples were labeled as Raw- 1, Raw- 2 and Raw- 3 respectively. 
Sampling: The collected raw turmeric was dried in a microwave oven (Gallenkamp) at $70 \pm 5^{\circ} \mathrm{C}$ and grinded to powder using a grinder. Powdered turmeric samples of the raw turmeric were then kept in polyethylene packets and stored in the refrigerator for analysis. Each spice sample was dried at $65^{\circ} \mathrm{C}$ for 48 hours before digestion. Nitric-perchloric acid digestion method (Zeng, 2004) was used for getting the sample solution. This method was performed in triplicate for each sample and hence $(3 \times 9=27)$ sample solutions were obtained from nine initial sample solutions.

Standard solution preparation: Standard solutions were prepared from stock solutions for the respective metal (Fe-1000, Mn-1000, Cu-1000, Zn-1000, Cr-1000, Ar-1000, Pb1000, Cd-1000; Kanto Chemical Co., Japan) in order to find the calibration curve.

Method: Concentration of the heavy metals (Lead, Cadmium, Chromium, Arsenic, Zinc, Iron, Copper, Manganese) in eight standard solutions and in nine different turmeric spice sample solutions were determined (Zeng, 2004) using Atomic Absorption Spectroscopy (AA-7000, Shimadju). Blank samples were made using only the reagents i.e. without the sample in order to eliminate any background concentration of metals in the entire study.

Statistical analysis: The data were subjected to one-way ANOVA. All of these data were processed using IBM SPSS (statistics - 23).

\section{RESULTS AND DISCUSSION}

Figure 1 to 3 show the results of heavy metals found in different types of turmeric powder sample viz. raw, unpacked bulk and packed branded. It is clear that though there was variation in heavy metal concentration in the unpacked bulk turmeric powder of different markets (Fig. 2) and packed branded turmeric powder of different brands (Fig- 3) but there was almost no variation in heavy metal concentration irrespective of the farmland where the raw turmeric was grown and collected (Fig. 1). It could be indicative that turmeric grown in different soils has same relative absorption or taking up capability of the respective heavy metal. On the other hand, variation in any specific heavy metal content (especially when the content is greater than the turmeric powder of raw turmeric products) in the unpacked bulk and packed branded products of turmeric powder is an indication of deliberate addition or addition of the heavy metal from the system during processing of the dried turmeric rhizome to turmeric powder. Anyway, the decreasing order of heavy metal in the raw turmeric powder was: $\mathrm{Cu}>\mathrm{Fe}>\mathrm{Mn}>\mathrm{Zn}>\mathrm{Pb}>\mathrm{Cr}>\mathrm{Cd}$ $>$ As and it was so because absorption capability of turmeric grown in soil is varied for different heavy metals. Negligible content of $\mathrm{Pb}$ and no content of $\mathrm{Cr}$ in the packed branded product of turmeric powder raised the question to the author about allegation of $\mathrm{Cr}$ in them (Garcia, 2000). 

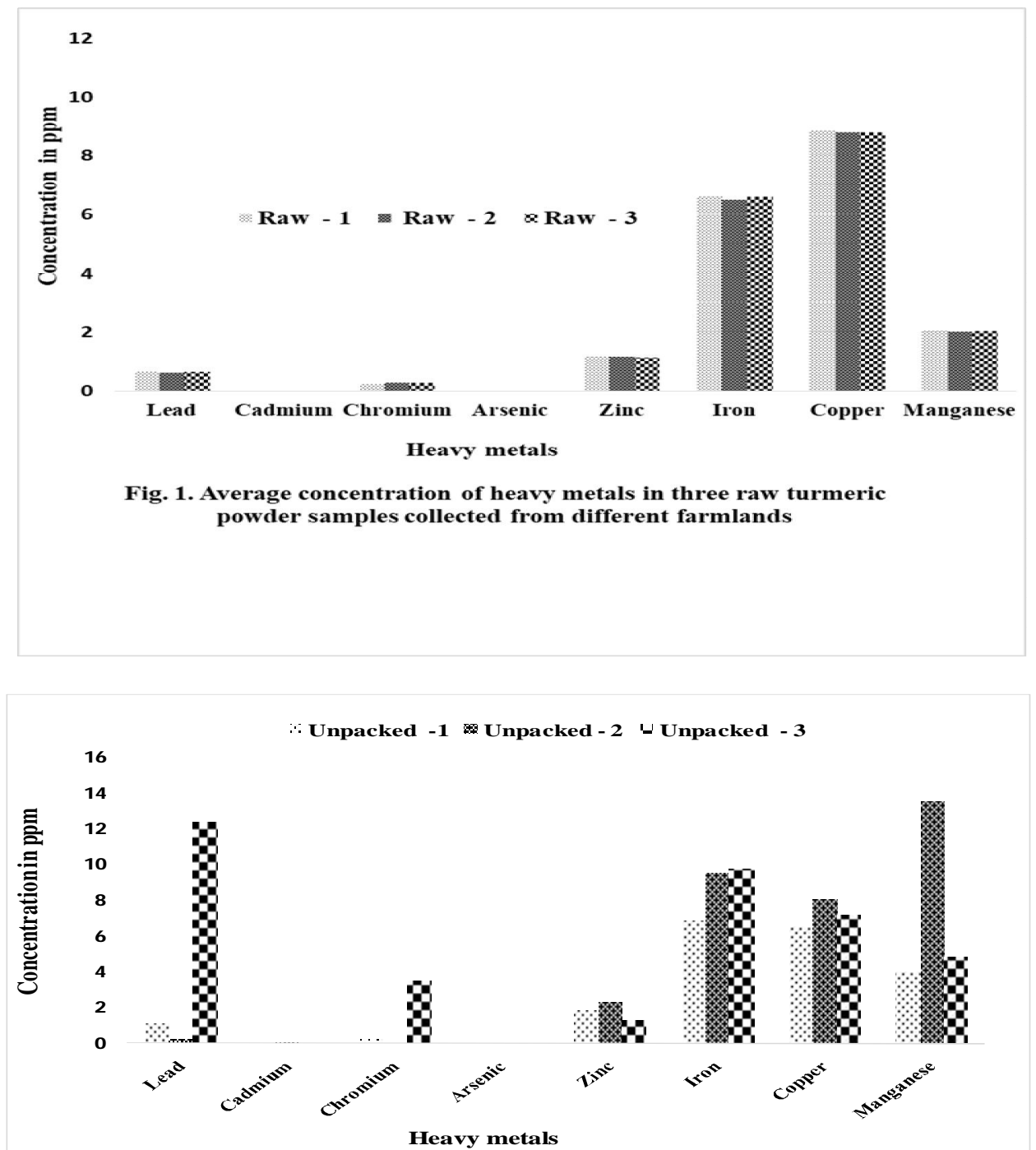

Fig. 2. Average concentration of heavy metals in unpacked bulk turmeric powders collected from different local markets 


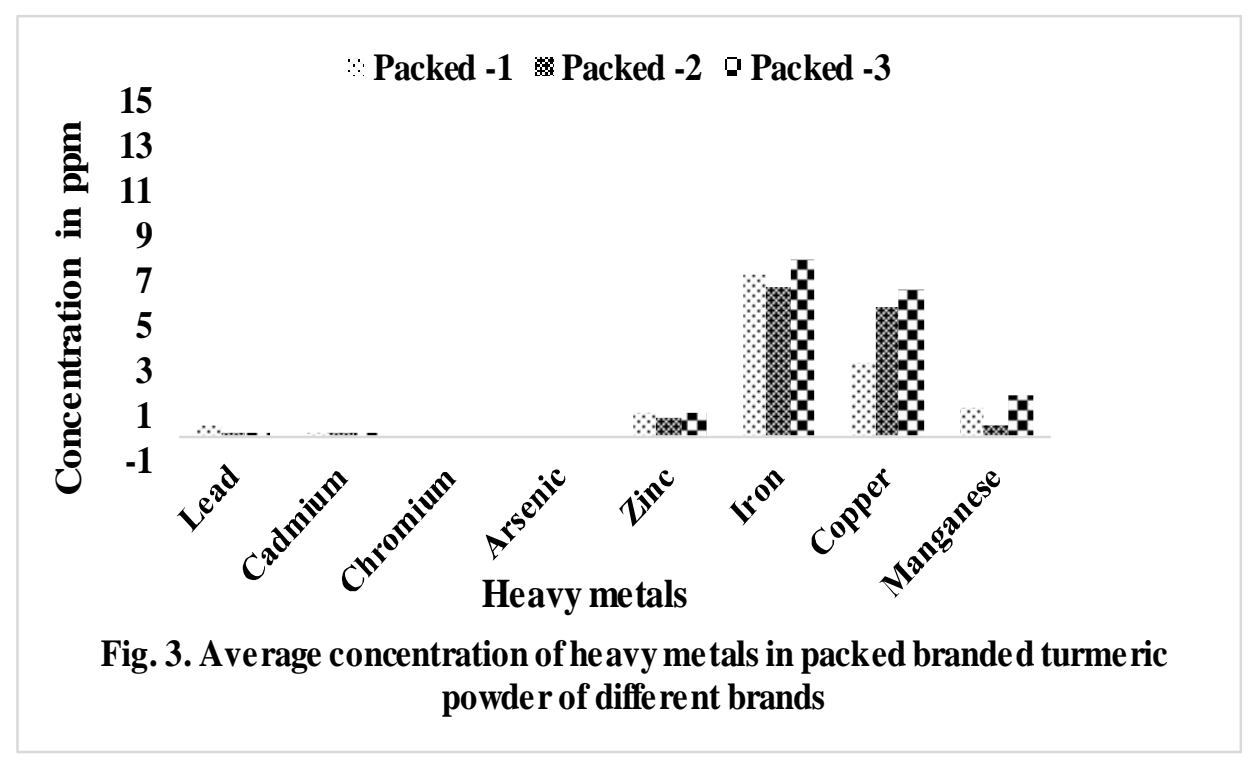

Mean contents of different heavy metals in different turmeric samples are shown in the Figure 4 and the observed results have been discussed below with respect to individual heavy metal content found:

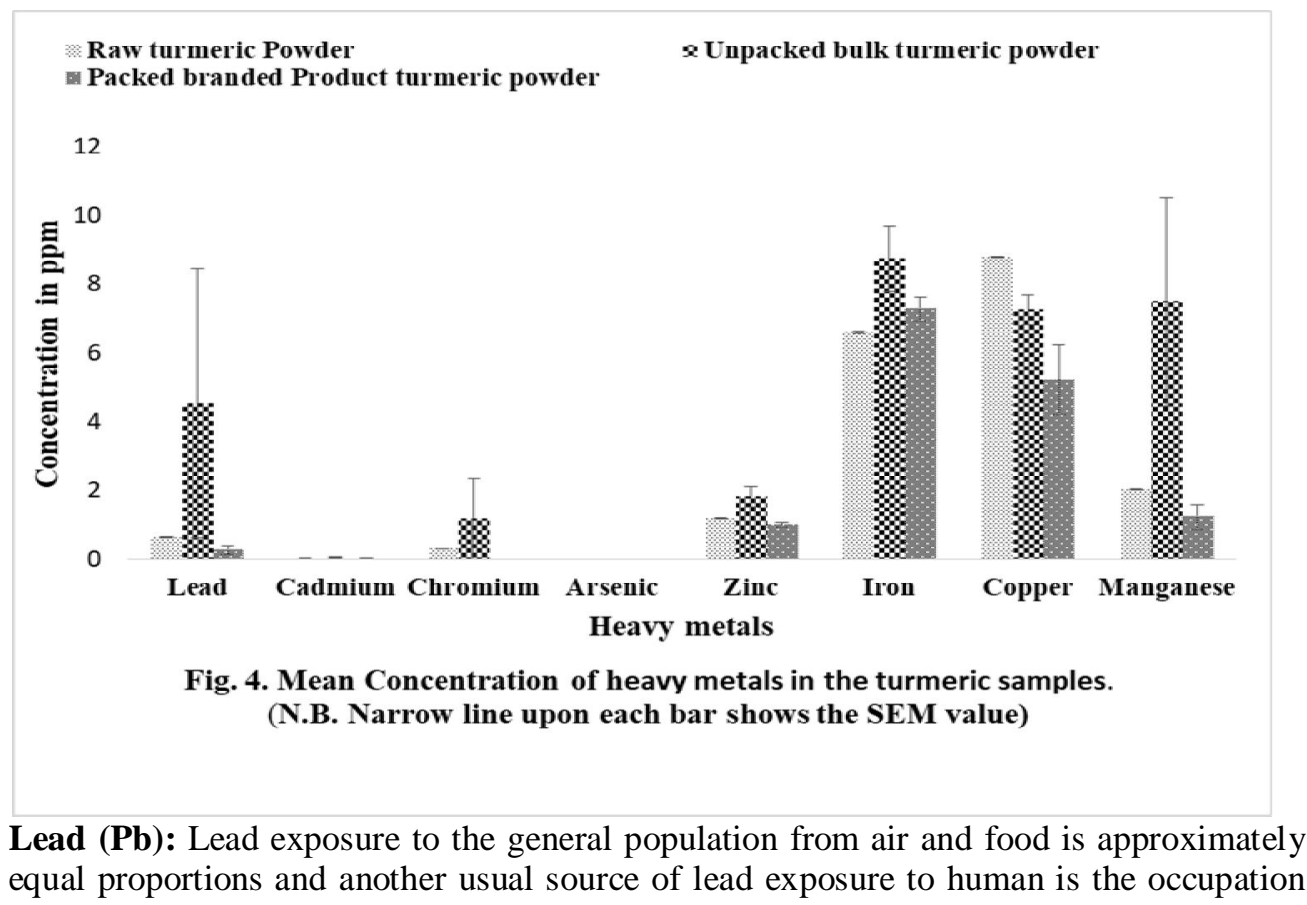


(Lars, 2003). Lead is a very toxic heavy metal for human body. Long time exposure to lead may cause memory deterioration, prolonged reaction time, reduced ability to understand and neurotoxicity. The most obvious symptom of lead poisoning is the disturbance of hemoglobin synthesis, anemia as well as cancer (Lars, 2003)

The highest concentration (12.3469 ppm) of lead was found in unpacked-3 sample which was beyond the standard permissible limit ( $6 \mathrm{ppm})$ recommended by WHO (Prabhangshu et al., 2015; Choi, 2011) and lowest in packed-2 sample (0.1263 ppm). Though excess level of lead compared to standard level was found in only one sample, it is alarming for our public health.

Cadmium (Cd): Cadmium is a very predominant toxic heavy metal. Smokers are greatly exposed to cadmium due to their cigarette smoking habits. The most widespread source of cadmium is the food which is exposed to normal non-smoking population in most of the countries (Lars, 2003). Cadmium exposure to human is very life threatening and is associated with chronic renal failure and skeletal damage (Lars, 2003)

Here all samples showed acceptable cadmium concentration compared to standard value (0.1 ppm) (Prabhangshu et al., 2015; Choi, 2011).

Chromium (Cr): Chromium is a very common trace element. There are many physiological roles of chromium in small concentration. Chromium promotes cellular glucose uptake as well as stimulate some enzymes in vitro. Chromium is important for the structure and metabolism of nucleic acids (David, 1989).

In this study all packed branded samples showed no concentration of chromium. We also found the concentration of chromium within the standard value (100 ppm) (Prabhangshu et al., 2015; Choi, 2011) in all unpacked bulk and raw samples.

Arsenic (As): Arsenic is an abundant metalloid that distributed greatly in rock, soil, water and air (Lars, 2003). In Bangladesh arsenic pollution is very predominant. Arsenic contamination occurs among population due to intake of food and drinking water. People who have chronically exposed to arsenic are at high risk of mortality from kidney, lung, and bladder cancer and the risk increases with increasing exposures (Lars, 2003). The concentration of arsenic in all samples was below the permissible limit (1.4 ppm), recommended by WHO (Prabhangshu et al., 2015; Choi, 2011).

Zinc (Zn): Zinc is an essential element due to its versatile function in the human body. Zinc plays an important role in the growth and has a recognized action on more than 300 enzymes by participating in their structure or their catalytic and regulatory actions (Marian \& Cosmos, 2010).

Highest concentration of $\mathrm{Zn}(2.3307 \mathrm{ppm})$ was found in the sample coded as unpacked-2 and lowest $(0.8425 \mathrm{ppm})$ in packed-2 sample. According to WHO, Zinc concentration in all of the spice samples were within the limit (100 ppm) (Prabhangshu et al., 2015; Choi, 
2011). The branded packed samples contain less concentration of $\mathrm{Zn}$ compared to unpacked bulk samples.

Iron (Fe): Iron is an essential element found in the earth which is mostly needed for the human. Many metabolic processes like, oxygen transport, DNA synthesis, and electron transport within the cells are mostly executed with iron. Iron is an essential part of hemoglobin which is needed for the production of red blood cells (Gupta, 2014). However, in this study the highest concentration $(9.7885 \mathrm{ppm})$ of Iron was found in the sample labelled as unpacked-3 and lowest $(6.5201 \mathrm{ppm})$ in raw- 2 spice sample. Iron concentration in all of the spice samples were within the limit (300 ppm) recommended by WHO (Prabhangshu et al., 2015; Choi, 2011). The concentration of Fe in most of the packed branded sample was comparatively lower than the unpacked bulk powder spice sample.

Copper $(\mathbf{C u})$ : Copper is a naturally occurring metallic element which is present in all animals and plants. It is needed in small amount in human and animals. The most important function of copper is that it acts as an essential component for different enzymes which are necessary for normal metabolic functions in human body. Anyway, higher dose of copper can cause the destruction of red blood cells, possibly resulting in anemia and chronic toxic level of copper can damage the liver and kidneys (Manju, 2015).

Highest concentration (8.8268 ppm) of $\mathrm{Cu}$ which was within the standard limit (50 ppm) (Prabhangshu et al., 2015; Choi, 2011) was found in the raw-1 spice sample and lowest (3.2694 ppm) in the packed-1 branded product sample.

Manganese (Mn): Like other trace elements, manganese is also an important one. Chronic exposure to excessive manganese level can cause a variety of psychiatric and motor disturbances, termed as manganism. Generally, exposure to ambient manganese air concentrations in excess of 5 micrograms $\mathrm{Mn} / \mathrm{m}^{3}$ can lead to Mn-induced symptoms (Khan et al., 2012).

Here, the highest concentration of $\mathrm{Mn}(13.5391 \mathrm{ppm})$ was found in unpacked-2 sample and lowest $(0.5377 \mathrm{ppm})$ in a packed-2. All samples showed acceptable Mn concentration compared to standard value $(100 \mathrm{ppm})$ recommended by WHO (Prabhangshu et al., 2015; Choi, 2011).

Conclusion: On the basis of the result of this study it can be said that the majority of the turmeric spice samples were safe in terms of the content of heavy metals. Only one unpacked bulk sample coded as unpacked-3 showed excess amount of lead (12.3469 ppm) which was almost double compared to standard value (6 ppm) recommended by WHO. Excessive use of these heavy metal through consuming the indicated turmeric powder may cause serious health hazards to customers. Proper monitoring of the extent of heavy metal in these spices would help to control the public health impact after taking these spices and also provide relevant data for the regulatory body. 


\section{REFERENCES}

Ajasa, A., Bello, M.O., Ibrahim, A.O., Ogunwande, I.A. and Olawore, N.O. 2004. Heavy trace metals and micronutrients status in herbal plants of Nigeria, Food Chem, 85: 67-71.

Choi, Y. Y. 2011. International/National Standards for Heavy Metals in Food, pp. 1-13.

David, L.W. 1989. The Nutritional Relationships of Chromium, Journal of Orthomolecular Medicine, 4(1): 17.

Garcia, E. 2000. Chromium levels in spices and aromatic herbs, Science of the Total Environment, 247: 51-56.

Gupta, C.P. 2014. Role of Iron (Fe) in Body, IOSR Journal of Applied Chemistry,7(11, Ver. II): 38-46.

Gupta, K.K., Bhattacharjee, S., Kar, S., Chakrabarty, S., Thakar, P., Bhattacharyya, G. and Srivastava, S.C. 2003. Mineral compositions of eight common spices. Soil and plant anal., 34: 681-693.

Hinneburg, I., Damien, D.H.J. and Hiltunen, R. 2006. Antioxidant activities of extract from selected culinary herbs and spices. Food Chem. 97:122.

Hirasa, K. and Takemasu, M. 1998. Spice Science and Technology, Marcel Decker Inc., New York.

https://www.govtlab.gov.hk/g/texchange/Stds\%20for\%20heavy\%20metals.pdf, [accessed on 5 December 2020].

Khan, K., Wasserman, G.A., Liu, X., Ahmed, E., Parvez, F. and Slavkovich, V. 2012. Manganese exposure from drinking water and children's academic achievement, Neurotoxicology, 33(1): 91-97.

Lars, J. 2003. Hazards of heavy metal contamination, British Medical Bulletin, 68: 170-179.

Manju, M. 2015. Effects of heavy metals on human health, International Journal on ResearchGRANTHAALAYAH, September: 1-7.

Marian, A.N. and Cosmos, O.A. 2010. Heavy metal content of some common spices available in markets in the Kumasi metropolis of Ghana, American Journal of Scientific and Industrial Research, 1(2): 158-163.

Prabhangshu, K.D., Milton, H., Mujib, A.S.M., Faridul, I., Mahmud, A. S. M., Samina, A. and Joardar, J.C. 2015. Heavy Metal Concentration in Some Common Spices Available at Local Market as well as Branded Spicy in Chittagong Metropolitan City, Bangladesh, Current World Environment, 10(1): 101-108.

Singh, V. and Garg, A.N. 2006. Availability of essential trace elements in Indian cereals, vegetables and spices using INAA and the contribution of spices to daily dietary intake, Food Chem, 94: 81-89.

Srinivasan, K. 2005. Spices as influencers of body metabolism: an overview of three decades of research, Food Res. Int. 38: 77-86.

Zeng, Y.H. 2004. Evaluating heavy metal contents in nine composts using four digestion methods, Elsevier Bioresource Technology, 95(1): 53-59. 